\title{
Cartesian Diver as a Density Comparator
}

\author{
Horace A. Bowman and Randall M. Schoonover
}

\author{
(March 25, 1965)
}

\begin{abstract}
A hydrostatic weighing system is described that provides independent values of apparent mass with a standard deviation of about 0.2 microgram. The definition of "independent" used here includes the requirement that the sample under observation be removed from the water, dried, and recleaned between measurements. This precision is between one and two orders better than existing hydrostatic balances, and permits high-quality density measurements without recourse to large sample sizes. The system is used as a comparator, hence the absolute accuracy of results can be no better than that of the standards used. Data are presented which were taken during experiments on two 2 -gram pieces of single crystal silicon, and the standard deviation in density of a single determination was computed to be $4.4 \times 10^{-7} \mathrm{~g} / \mathrm{cm}^{3}(0.22 \mathrm{ppm})$.

The system is particularly well suited to detection of slight density changes in small size samples. In this service, it is not subject to the requirement for high accuracy standards. Data are reported on density changes of about $50 \mathrm{ppm}$ that occurred in a 250 milligram ceramic crystal. Two independent determinations on this change differed by only 7 percent.
\end{abstract}

\section{Introduction}

The density of an irregularly shaped object is usually determined by a combination of air and water weighing in which the apparent mass of the object is determined in both media. The apparent mass in air, $A$, is determined on a balance in the usual manner. The apparent mass in water, $B$, is determined by suspending the object from one pan of the balance by a fine wire into a body of water. The mass, $M$, and volume, $V$ (the ratio of which is density), result immediately from a simultaneous solution of

$$
\begin{aligned}
& A=M-\rho_{A} V \text { (air weighing) } \\
& B=M-\rho_{W} V \text { (water weighing) }
\end{aligned}
$$

where $\rho_{A}$ is the density of the air displaced by the object during the air weighing, and $\rho_{W}$ the density of the water displaced by the object during the hydrostatic weighing.

The main limitation in the above scheme occurs in the determination of $B$. There are two reasons for this:

(1) Although we know the density of a particular sample of water to almost two orders better than we know the density of a particular sample of air, water density is about three orders greater than that of air. Hence, the uncertainty in $\rho_{W} V$ is greater than that of $\rho_{A} V$.

(2) In water weighing, the variability of nonbuoyant forces is of much greater magnitude than those occurring in air weighing. First, there are variable momentum forces associated with turbulence and convective currents in water which act on the object being weighed. Such forces also exist in air weighing but to a much smaller extent. Second, there is variability in surface tension forces associated with the meniscus surrounding the point where the support wire penetrates the water surface. Under nonideal conditions, these forces may vary by $10 \mu \mathrm{g}$ or more.

Thus, the accuracy in a measured value of $B$ is limited by our knowledge of $\rho_{W}$, and the reproducibility of the measured value is limited by the variability of the nonbuoyant forces mentioned above.

For a given hydrostatic weighing system the absolute value of the variability (due to nonbuoyant forces) is largely independent of load. Hence, to achieve improved values of percentage reproducibility in $B$, we must use samples of very large sizes.

Unfortunately, objects for which density determinations have the maximum scientific value are rarely available in samples of unlimited sizes. It is seldom that samples above $2 \mathrm{~g}$ are obtainable, and they are usually of fractional-gram size. Such items as uniformly irradiated crystals, samples of maximum purity substances, and balance sensitivity weights, usually weigh $250 \mathrm{mg}$ or less. For a 250$\mathrm{mg}$ object, a variability of $10 \mu \mathrm{g}$ in the nonbuoyant forces would result in a variability in $B$ of about $40: 10^{6}$ - a highly unsatisfactory measurement for many technical purposes.

In the Cartesian diver system to be described, it is possible to determine $B$ of a $250-\mathrm{mg}$ object to a reproducibility (standard deviation) of about $1: 10^{6}$. The reason for this is that the two major sources of variability in ordinary hydrostatic weighing do not exist in the diver system or are minimized:

(A) No portion of the diver structure penetrates a water surface, so uncertainties caused by surface tension do not exist.

(B) The diver system is operated at a nominal temperature of $4{ }^{\circ} \mathrm{C}$; hence, nonideal thermostating does not result in variability of water density. In the absence of density gradients (other than those 
caused by gravity) convection currents cannot become established, and turbulence damps out quickly. Thus momentum forces are minimized. It is generally considered impractical to perform ordinary hydrostatic weighing at $4{ }^{\circ} \mathrm{C}$.

\section{Description of the System}

The Cartesian diver is not a new device. A review of prior art is given by Chiarulli and Chilton [1]. ${ }^{1}$ Recent work by Haller and Calcamuggio [2] and Spaepen [3] has raised the state of the art greatly.

Basically the diver, figure 1 , is a hollow, compressible body with a closed surface to which are attached various hooks, guides, and reticles to facilitate loading, manipulation, and observation. When such a body is immersed in water and the pressure in the water is increased, the positive buoyancy of the body will decrease or increase respectively, depending upon whether the compressibility of the diver is greater than or less than that of water. If diver compressibility is equal to that of water, buoyancy is independent of pressure.

${ }^{1}$ Figures in brackets indicate the literature references at the end of this paper.

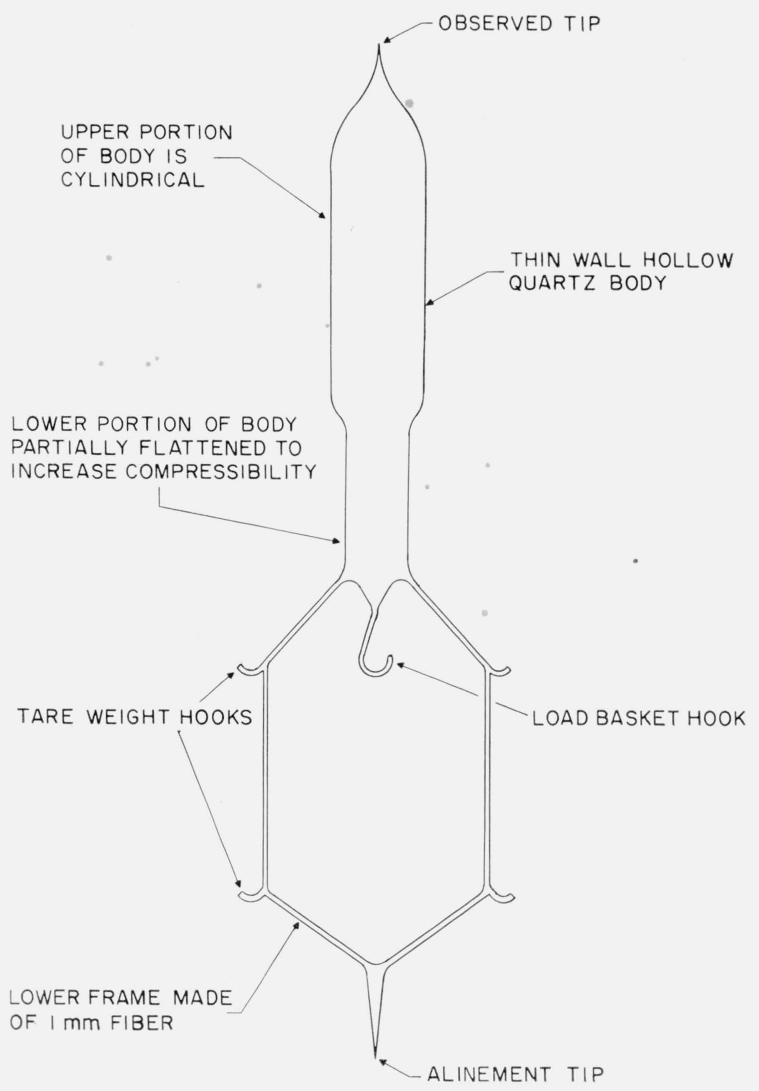

Figure 1.
Our most useful diver is made of fused quartz (vitrified silica) and weighs about $5 \mathrm{~g}$. It displaces about $10 \mathrm{~cm}^{3}$; hence in water it has a positive buoyancy of about $5 \mathrm{~g}$. It has a very thin wall so it is quite compressible. In practice it is loaded by the object to be measured and enough tare weight to cause it to sink slowly in water at $4{ }^{\circ} \mathrm{C}$. The pressure system, figure 2 , is then closed and the water pressure reduced slightly. This causes the diver volume to expand, thereby increasing diver buoyancy. This causes the loaded diver to stop falling and begin to rise.

There is a pressure gradient in the water, due to the gravity field, so that as the diver rises, it moves into a region of lower pressure. This causes additional expansion and an increase in buoyance, so the diver is accelerated upward. Conversely, when the water pressure is increased, the diver body is compressed which results in smaller buoyance. The diver will then sink. As it sinks into a region of higher pressure, additional buoyancy is lost and the diver is accelerated downward. Thus, the gravity pressure gradient in the fluid always accelerates diver motion, and as a result, there is no position of stable equilibrium.

On the other hand, had the diver compressibility been less than that of water, the reverse set of circumstances would have held. Under such conditions, the pressure gradient in the water would always impede the diver motion and a position of stable equilibrium would exist. It is possible to operate a diver system under either condition, but practical considerations such as load range and sensitivity led to our choice of a diver more compressible than water.

Diver motion is observed through a rigidly mounted microscope and a system of windows and mirrors. The optical center of this system is carefully adjusted horizontally, and the horizontal plane within the diver chamber containing the optical center is called the reference plane. Although (as explained above) there is no level of stable equilibrium for the diver in the system, there is a pressure which will result in the loaded diver having a density precisely equal to the density of the water it displaces when the observed upper tip of the diver is in the reference plane. This pressure is called the equilibrium pressure, $P_{E}$, and it can be determined by averaging the two pressures which cause the diver to move upward and downward across a vertical range defined by an eyepiece reticle and extending about $0.013 \mathrm{~cm}$ above and below the reference plane in equal intervals of time (usually about $30 \mathrm{sec}$ ).

When the pressure is very close to $P_{E}$, we are justified in assuming that the average velocity, $y$, of the diver, during its transit of the range, is nearly linear with pressure. Thus, when the average rising velocity, $y_{R}$, does not precisely equal the average falling velocity, $y_{F}$, an acceptable value of $P_{E}$ can be calculated from the formula

$$
\frac{P_{E}-P_{R}}{P_{F}-P_{R}}=\frac{-y_{R}}{y_{F}-y_{R}} .
$$




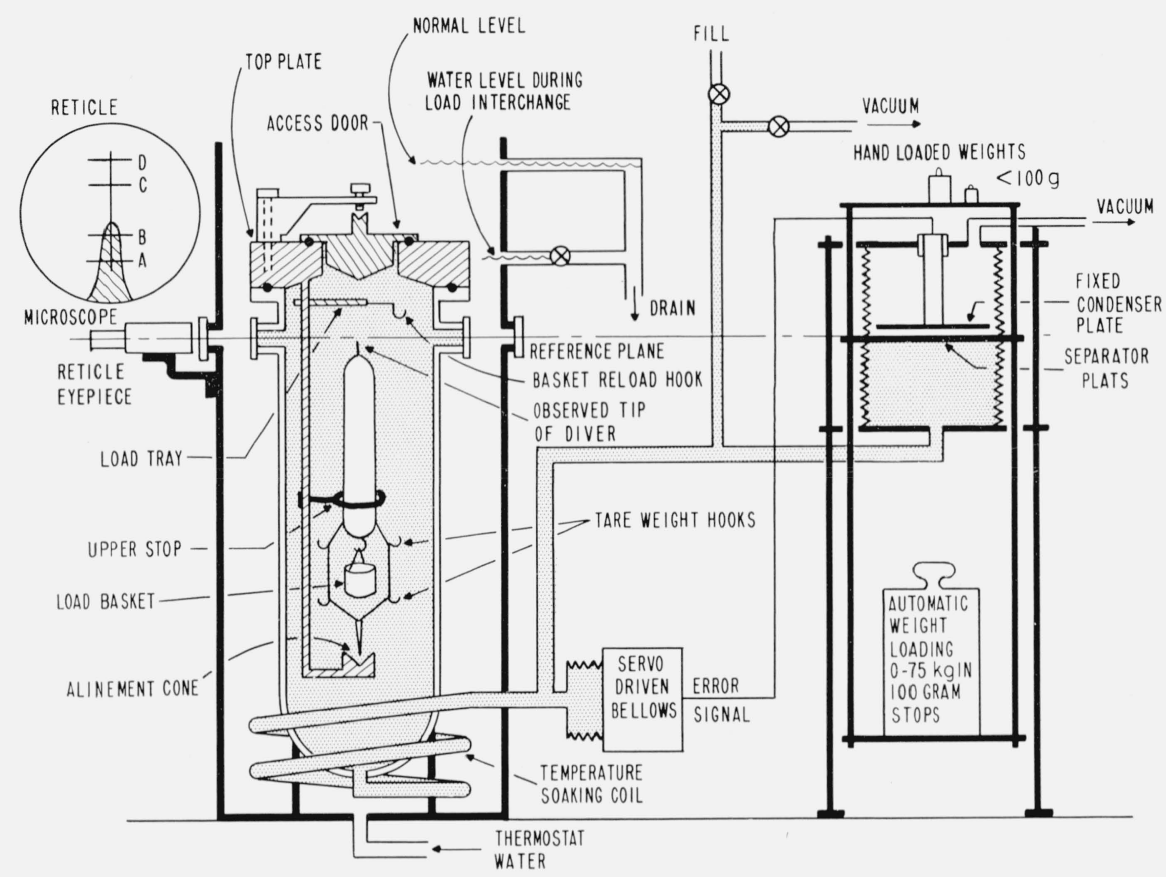

Figure 2.

Alternatively, there is a quick graphic solution, which we used, illustrated in figure 3 .

\section{Pressure System}

Our pressure regulator system is a modification of the two-bellows barostat developed by D.P. Johnson [4] for use in the NBS barometer calibration service. It consists of two stainless steel bellows mounted one above the other. The upper bellows is evacuated, and the lower is water-filled and connected to the diver chamber. The upper end of the upper bellows and the lower end of the lower bellows are rigidly attached to the frame. The two bellows are connected mechanically together by a freely floating separator plate. Under such circumstances, the pressure developed in the water in the lower chamber is directly proportional to the deadweight loading of the separator plate. The effective areas of the bellows are such that a $76 \mathrm{~kg}$ deadweight load on the separator plate results in about 1 -atm pressure being developed in the lower chamber. The loading of the separator plate is conveniently changed in increments of about $100 \mathrm{~g}$, from a minimum of 2 $\mathrm{kg}$ (the tare load) to $85 \mathrm{~kg}$, by a semiautomatic loading machine developed by David Sklar, Design Development Laboratories, for the purpose. A small tray on top of the assembly is used to receive additional small hand-loaded weights of between 1 and $100 \mathrm{~g}$ (see fig. 2).

The separator plate is electrically connected as the moving plate of a two-plate variable capacitor. The fixed plate is rigidly attached inside of the

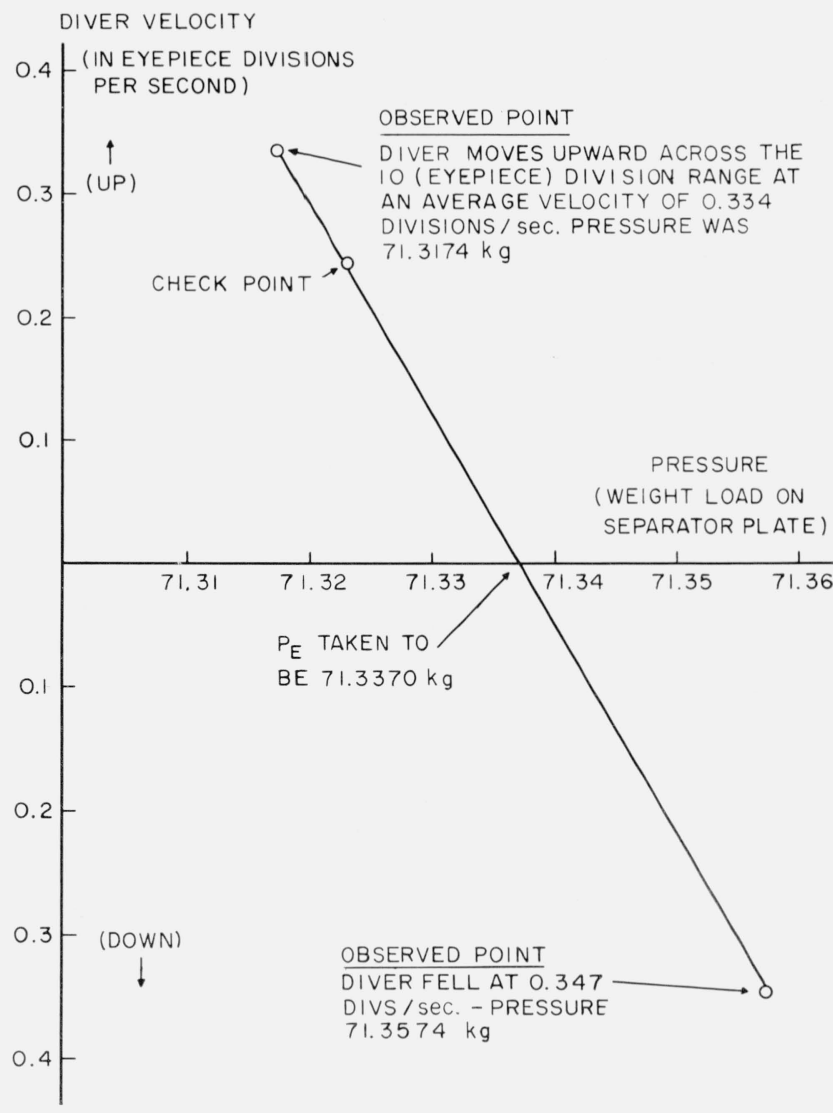

Figure 3. 
evacuated bellows, about $0.013 \mathrm{~cm}$ above the midpoint of the $0.025 \mathrm{~cm}$ free travel allowed the separator plate by its stops. The capacitance between the fixed and moving plates is fed into a Wien bridge oscillator and discriminator, which provides servo power to drive a motor-driven bellows connected in the hydraulic system, in such a direction that the separator plate is maintained at the midpoint of its allowed travel, regardless of loading.

With this arrangement the two-bellows assembly is used as an error signal generator and actual pressure changes are made by the servobellows. Inasmuch as the separator plate remains at the same vertical level, regardless of pressure, the effects of the elastic properties of the stainless steel bellows are largely eliminated.

The elastic properties of one of the divers are such that the diver buoyancy changes by $1 \mu \mathrm{g}$. when the separator plate load is changed by $12 \mathrm{~g}$. Inasmuch as diver buoyancy on differences is constant to about $2 / 10 \mu \mathrm{g}$, it can be inferred that the short term stability of drift of the pressure regulator is about $2 \times 10^{-5} \mathrm{~atm} / \mathrm{hr}$. This is consistent with other estimates of stability of similar devices [5].

As use of the diver system does not require absolute knowledge of pressure, no effort has been made to calibrate the system in absolute terms. In use, pressures developed are stated in terms of the kilogram load on the separator plate, which is acceptably linear with water pressure.

\section{Use of the Diver-Density Measurements}

If $G_{1}$ is the mass of water displaced by the Cartesian diver body at some pressure, then

$$
G_{1}=\rho_{1} v_{1}
$$

where $\rho_{1}$ is the density of water at that pressure, and $v_{1}$ the associated diver volume. Both $\rho_{1}$ and $v_{1}$ are functions of pressure, and $G$ will increase or decrease with increasing pressure depending upon whether the compressibility of water is greater than or less than that of the diver body. $\Delta G$ is not a perfectly linear function of $\Delta P$. We have carefully measured the nonlinear term and found

$$
\frac{\Delta^{\prime} G}{\Delta P^{\prime}}=8 \times 10^{-8} \mathrm{~g} / \mathrm{cm} \mathrm{Hg} / \mathrm{cm} \mathrm{Hg} .^{2}
$$

Integrating twice gives us

$$
G=\left(4 \times 10^{-8}\right) P^{2}+C_{1} P+C_{2}
$$

where $C_{1}$ and $C_{2}$ are the constants of integration introduced thereby. This term adequately represents the mass of water displaced by the diver as a function of pressure.

2 Although, as previously stated, the pressure system has not been calibrated in absolute terms, within 1 percent, a load change of $1 \mathrm{~kg}$ on the separator plate results in a pressure change of $1 \mathrm{~cm} \mathrm{Hg}$.
The experiment consists of loading the diver, first with two standards, S1 and S2, and noting the equilibrium pressures, $P_{\mathrm{s} 1}$ and $P_{\mathrm{S} 2}$ associated with each. Following this, the unknown object, $X$, is placed on the diver and $P_{x}$ observed. The masses, $M_{\mathrm{S} 1}$ and $M_{\mathrm{S} 2}$, and the volumes, $V_{\mathrm{S} 1}$ and $V_{\mathrm{S} 2}$, of the two standards are assumed known. The equilibrium equation of the diver is

$$
M_{D}-G+M_{L}-\rho_{W} V_{L}=0
$$

where $M_{D}$ is the diver mass, $M_{L}$ and $V_{L}$ the mass and volume, respectively, of the load and $\rho_{W}$ the density of water at the equilibrium pressure. As pointed out in the introduction $M_{L}-\rho_{W} V_{L}$ is the apparent mass of the load in water, $B_{L}$. For each of the three loads placed on the diver during the experiment, we may write an equilibrium equation

$$
\begin{aligned}
& M_{D}-\left(4 \times 10^{-8}\right) P_{\mathrm{S} 1}^{2}-C_{1} P_{\mathrm{S} 1}-C_{2}+B_{\mathrm{S} 1}=0 \\
& M_{D}-\left(4 \times 10^{-8}\right) P_{\mathrm{S} 2}^{2}-C_{1} P_{\mathrm{S} 2}-C_{2}+B_{\mathrm{S} 2}=0 \\
& M_{D}-\left(4 \times 10^{-8}\right) P_{X}^{2}-C_{1} P_{X}-C_{2}+B_{X}=0
\end{aligned}
$$

subtracting the second equilibrium equation from the first, and then the third from the first gives us two difference equations

$-\left(4 \times 10^{-8}\right)\left(P_{\mathrm{S} 1}^{2}-P_{\mathrm{S} 2}^{2}\right)-C_{1}\left(P_{\mathrm{S} 1}-P_{\mathrm{S} 2}\right)+\left(B_{\mathrm{S} 1}-B_{\mathrm{s} 2}\right)=0$ $-\left(4 \times 10^{-8}\right)\left(P_{\mathrm{S} 1}^{2}-P_{X}^{2}\right)-C_{1}\left(P_{\mathrm{S} 1}-P_{X}\right)+\left(B_{\mathrm{S} 1}-B_{X}\right)=0$.

The first difference equation may be immediately solved for a numerical value of $C_{1}$

$$
C_{1}=\frac{\left(B_{\mathrm{S} 1}-B_{\mathrm{S} 2}\right)-4 \times 10^{-8}\left(P_{\mathrm{S} 1}^{2}-P_{\mathrm{S} 2}^{2}\right)}{\left(P_{\mathrm{S} 1}-P_{\mathrm{S} 2}\right)}
$$

and with this value of $C_{1}$ inserted in the second difference equation, we may solve for the apparent mass of the unknown in water, $B_{X}$.

$$
B_{X}=B_{\mathrm{S} 1}-4 \times 10^{-8}\left(P_{\mathrm{S} 1}^{2}-P_{X}^{2}\right)-C_{1}\left(P_{\mathrm{s}_{1}}-P_{X}\right) .
$$

This experiment demands a minimum of three observations $-P_{\mathrm{S} 1}, P_{\mathrm{S} 2}$, and $P_{X}$. Our system has drift associated with electronic drift, drift in ambient conditions and (probably) other sources. In order to minimize the effect of this drift we use one of our loads as a drift monitor. This load is observed every second observation. For an experiment with only one unknown the observation format would contain five observations taken at uniform intervals, thus: $\quad P_{\mathrm{s} 1}-P_{\mathrm{s} 2}-P_{\mathrm{s} 1}-P_{X}-P_{\mathrm{s} 1}$. The value of $\left(P_{S 1}-P_{S 2}\right)$, required in the calculations shown above is obtained by subtracting the observed value of $P_{\mathrm{s} 2}$ from the average of the first two $P_{\mathrm{S} 1}$ 's. $\left(P_{\mathrm{S} 1}-P_{X}\right)$ is obtained in a similar manner. The three observed values of $P_{\mathrm{s} 1}$ are averaged to give the effective value of $P_{\mathrm{S} 1}$ during the experiment. Effective values of $P_{\mathrm{S} 2}$ and $P_{X}$ used in calculations of $C_{1}$ and $B_{X 1}$ are obtained by applying the difference terms to this effective value. 
The values of water density used in the calculation of apparent mass in water of the standards (from assigned values of mass and volume) are based upon an assumed density of $0.999973 \mathrm{~g} / \mathrm{cm}^{3}$ at $4^{\circ} \mathrm{C}$ and at 1 atm, and corrected for departure from $1 \mathrm{~atm}$ of the effective values of observed pressure. Errors in the assumed value of water density exert only a second-order effect on the calculated density of the unknown, because our density knowledge is primarily obtained from the density standards used in the experiments. The water is merely the comparison medium.

The diver system is currently being used in several density studies not pertinent to this report. To illustrate typical diver operation, some data from these studies will be presented here. Table 1 shows the observed raw data taken during measurements on two imperfect silicon crystals, X1 and X2. The standards used in this experiment were two perfect silicon crystals, S1 and S2, whose assigned density value was $2.3290040 \mathrm{~g} / \mathrm{cm}^{3}$. The observed values of $P_{E}$ and the pressure differences were calculated from values of rising and falling pressures and velocities as previously explained. This table shows data taken during four independent experiments performed during January 1965, and the average value of a group of nonindependent similar experiments performed on the same crystals during the previous November. Between each experiment all crystals were removed from the hydrostatic system and dried and recleaned.

TABLE 1

\begin{tabular}{|c|c|c|c|c|c|c|c|c|}
\hline & \multicolumn{2}{|c|}{ Falling } & \multicolumn{2}{|c|}{ Rising } & \multirow{2}{*}{$\begin{array}{c}\text { Ob- } \\
\text { served } \\
P_{E}\end{array}$} & \multirow[b]{2}{*}{$P_{\mathrm{S} 1}-P_{\mathrm{X} 1}$} & \multirow[b]{2}{*}{$P_{\mathrm{S} 1}-P_{\mathrm{X} 2}$} & \multirow[b]{2}{*}{$P_{\mathrm{s} 1}-P_{\mathrm{s} 2}$} \\
\hline & Pressure & $\begin{array}{l}\text { Ve- } \\
\text { locity }\end{array}$ & Pressure & $\begin{array}{c}\text { Ve- } \\
\text { locity }\end{array}$ & & & & \\
\hline $\mathrm{S} 1$ & 66.8010 & 0.2183 & 66.7310 & 0.1529 & 66.7600 & \multirow{7}{*}{+2.5699} & \multirow{7}{*}{+1.7221} & \multirow{7}{*}{+2.6829} \\
\hline $\mathrm{X}_{1}$ & 64.2264 & .1779 & 64.1564 & .1975 & 64.1932 & & & \\
\hline $\mathrm{S} 1$ & 66.8010 & .1922 & 66.7310 & .1902 & 66. 7662 & & & \\
\hline $\mathrm{X}_{2}$ & 65.0809 & .1678 & 65. 0109 & .2092 & 65.0495 & & & \\
\hline S1 & 66.8110 & .1833 & 66.7410 & .1952 & 66.7770 & & & \\
\hline $\mathrm{S} 2$ & 64.1246 & .1772 & 64.0546 & .1803 & 64. 0923 & & & \\
\hline S1 & 66.8110 & .2024 & 66.7410 & .1729 & 66.7735 & & & \\
\hline S1 & 66.8210 & .1799 & 66.7510 & .1960 & 66.7874 & \multirow{7}{*}{ 2. 5673} & \multirow{7}{*}{ 1. 7213} & \multirow{7}{*}{2.6771} \\
\hline $\mathrm{X}_{1}$ & 64.2459 & .1492 & 64.1859 & .1723 & 64. 2177 & & & \\
\hline $\mathrm{S} 1$ & 66.8210 & .2024 & 66.7510 & .1678 & 66.7825 & & & \\
\hline $\mathrm{X}_{2}$ & 65.1009 & .1766 & 65.0309 & .1909 & 65. 0675 & & & \\
\hline $\mathrm{S} 1$ & 66.8300 & .1872 & 66.7600 & .1882 & 66. 7950 & & & \\
\hline S2 & 64.1464 & .1818 & 64.0764 & .1973 & 64.1114 & & & \\
\hline S1 & 66.8210 & .2155 & 66.7410 & .2222 & 66.7820 & & & \\
\hline $\mathrm{S} 1$ & 66.9500 & .2059 & 66.8700 & .2198 & 66.9110 & \multirow{7}{*}{ 2. 5554} & \multirow{7}{*}{ 1. 7176} & \multirow{14}{*}{ 2. 6717} \\
\hline X1 & 64.3851 & .1792 & 64.3151 & .1981 & 64.3522 & & & \\
\hline S1 & 66.9400 & .1912 & 66.8700 & .1816 & 66.9042 & & & \\
\hline $\mathrm{X}_{2}$ & 65.2201 & .1728 & 65.1501 & .2015 & 65.1882 & & & \\
\hline S1 & 66.9500 & .2183 & 66.8700 & .1922 & 66.9075 & & & \\
\hline S2 & 64.2859 & .2309 & 64.2159 & .1165 & 64.2395 & & & \\
\hline S1 & 66.9500 & .1930 & 66.8800 & .1938 & 66.9150 & & & \\
\hline $\mathrm{S} 1$ & 66.9792 & .1961 & 66. 9092 & .1732 & 66.9425 & \multirow{7}{*}{ 2. 5456} & \multirow{7}{*}{ 1. 7065} & \\
\hline $\mathrm{S} 2$ & 64.3159 & .1880 & 64.2459 & .2020 & 64.2825 & & & \\
\hline S1 & 66.9792 & .2079 & 66.8992 & .2160 & 66.9401 & & & \\
\hline $\mathrm{X}_{2}$ & 65.2797 & .2326 & 65.2097 & .1437 & 65.2365 & & & \\
\hline S1 & 66.9792 & .1859 & 66.9092 & .2000 & 66.9458 & & & \\
\hline $\mathrm{X} 1$ & 64.4259 & .1552 & 64.3559 & .2174 & 64.3970 & & & \\
\hline S1 & 66.9792 & .2150 & 66.8992 & .2104 & 66.9395 & & & \\
\hline \multicolumn{6}{|c|}{$\begin{array}{l}\text { Average of points taken in November (second } \\
\text { silicon) }\end{array}$} & 2.5745 & 1. 7258 & 2. 6858 \\
\hline
\end{tabular}

Table 2 shows the calculated values of effective $P_{E}$ and the assumed $\rho_{W}$ associated with these values.
The apparent masses in water of the standards is based upon assigned true mass values of $M_{\mathrm{S} 1}=2.0000912 \mathrm{~g}$ and $M_{\mathrm{s} 2}=2.0004884 \mathrm{~g}$. The effective values of $C_{1}$ were obtained as previously described and they led to the values of apparent masses in water of the unknown cyrstals.

TABLE 2

\begin{tabular}{|c|c|c|c|c|c|}
\hline & & Crystal S1 & Crystal S2 & Crystal X1 & Cyrstal X2 \\
\hline Effective $P_{E}$ & $\begin{array}{l}1 \\
2 \\
3 \\
4 \\
5\end{array}$ & $\begin{array}{l}\text { 66. } 7692 \\
66.7868 \\
66.9094 \\
66.9420 \\
67.7366\end{array}$ & $\begin{array}{l}64.0863 \\
64.1097 \\
64.2377 \\
64.2832 \\
65.0508\end{array}$ & $\begin{array}{l}64.1993 \\
64.2195 \\
64.3540 \\
64.3964 \\
65.1621\end{array}$ & $\begin{array}{l}65.0471 \\
65.0655 \\
65.1918 \\
65.2355 \\
66.0108\end{array}$ \\
\hline Assumed $\rho W$ & $\begin{array}{l}1 \\
2 \\
3 \\
4 \\
5\end{array}$ & $\begin{array}{r}0.999678 \\
678 \\
679 \\
679 \\
684\end{array}$ & $\begin{array}{r}0.9999660 \\
660 \\
661 \\
662 \\
667\end{array}$ & $\begin{array}{c}0.999661 \\
661 \\
662 \\
663 \\
668\end{array}$ & $\begin{array}{r}0.9999667 \\
667 \\
668 \\
668 \\
673\end{array}$ \\
\hline$B$ of standards & $\begin{array}{l}1 \\
2 \\
3 \\
4 \\
5\end{array}$ & $\begin{array}{r}\text { 1. } 1413435 \\
1.1413435 \\
3435 \\
3434 \\
3430\end{array}$ & $\begin{array}{r}1.1415717 \\
1.1415717 \\
5716 \\
5716 \\
5711\end{array}$ & & \\
\hline$C_{1}$ & $\begin{array}{l}1 \\
2 \\
3 \\
4 \\
5\end{array}$ & $\begin{array}{r}-0.00009028 \\
9047 \\
9062 \\
9109 \\
9025\end{array}$ & \multicolumn{3}{|c|}{ Same values apply to all four columns. } \\
\hline$B$ of unknowns & $\begin{array}{l}1 \\
2 \\
3 \\
4 \\
5\end{array}$ & & & $\begin{array}{r}1.1415619 \\
5623 \\
5617 \\
5620 \\
5616\end{array}$ & $\begin{array}{r}1.1414900 \\
4902 \\
4901 \\
4900 \\
4896\end{array}$ \\
\hline
\end{tabular}

As pointed out in the introduction, we may obtain values of $M_{X}$ and $V_{X}$ from a simultaneous solution of the air weighing and the water weighing equations. Alternatively we may enter the water weighing equation with the value of $B_{X}$ obtained with the diver and a previously determined $M_{X}$ and solve for the density of the unknown, $\rho_{X}$.

$$
\rho_{X}=\frac{\rho_{W}}{B_{X} / M_{X}-1}
$$

where $\rho_{W}$ is the assumed water density at pressure $P_{X}$. Very careful analysis of this point will show that the two methods are nearly identical. The values of $\rho_{X}$ calculated from the $B_{X}$ 's determined with the diver and $M_{X 1}=2.0004774 \mathrm{~g}$ and $M_{X 2}=2.0003478 \mathrm{~g}$ were:

\begin{tabular}{|c|c|c|}
\hline & Crystal X1 & Crystal X2 \\
\hline 6.Januarv & 2. 3289950 & 2. 3290012 \\
\hline 7 January & 2. 3289958 & 2. 3290018 \\
\hline 8 January _. _ & 2. 3289944 & 2. 3290017 \\
\hline 9 January _._. & 2. 3289950 & 2. 3290015 \\
\hline Nov. Avg $\ldots \ldots \ldots$ & 2. 3289956 & 2. 3290019 \\
\hline Average_. & 2. 3289951 & 2. 3290016 \\
\hline
\end{tabular}

Pooled standard deviation $=4.4 \times 10^{-7} \sim 0.22 \mathrm{ppm}$. 


\section{Use of the Diver System-Density Changes}

There is widespread scientific interest in the measurement of slight density changes and density differences as well as in the measurement of absolute density itself. The Cartesian diver system is particularly well-suited to determination of changes and differences because of its ability to provide high precision data on samples of small size. In problems such as determination of density differences between nominally identical materials but having slightly different physical properties (such as between hard drawn and annealed wire), or determination of small density changes when a material is exposed to a density-modifying process (such as UV irradiation), homogeneity of the sample is usually of prime importance. Homogeneity can frequently be verified or inhomogeneity evaluated in samples of a few hundred milligrams, but it is frequently impractical or impossible to do so in samples of several grams. Some density modifying processes can provide homogeneous density changes only in small samples, as, for example, processes depending upon $\mathrm{x}$-ray beams that have limited diameters or penetrating powers.
In measuring density changes in an object subjected to a density modifying process, the diver system is largely free of the requirements for high accuracy standards. If the two standards are cut from the same piece of parent material from which the object of interest is cut, and to about the same geometry, then we are justified in assuming that the handbook value of the density of the material applies to the standards absolutely.

The diver was recently called upon to measure the change in density of a single crystal sample of rutile weighing less than $260 \mathrm{mg}$, when the stoichiometry was altered by thermal reduction. The standards used were cut from adjacent positions in the same boule from which the object of interest was cut. All three crystals were carefully weighed and two independent measurements on the apparent mass in water of the unknown, $B_{X}$, were made based on the assumption that the density of the standards was $4.249 \mathrm{~g} / \mathrm{cm}^{3}$.

The crystal of interest was partially reduced as called for in the experimental plan and was then reweighed. Two additional observations were made upon $B_{X}$. The data of interest is shown below:

\begin{tabular}{|c|c|c|c|c|}
\hline \multirow{3}{*}{$\begin{array}{l}\text { Weight of crystal of interest } \ldots \\
\text { Two measured values of } B_{X}\end{array}$} & \multicolumn{2}{|c|}{ Before modification } & \multicolumn{2}{|c|}{ After modification } \\
\hline & \multicolumn{2}{|c|}{$0.2586061 \mathrm{~g}$} & \multicolumn{2}{|c|}{$0.2585972 \mathrm{~g}$} \\
\hline & 0.1977429 & 0.197426 & 0.1977389 & 0.1977388 \\
\hline Two calculated values of $\rho_{X--}$ & 4. 248973 & 4. 248952 & 4. 249169 & 4. 249162 \\
\hline Average $\rho_{X} \ldots$ & \multicolumn{2}{|c|}{ 4. 248962} & \multicolumn{2}{|c|}{ 4. 249166} \\
\hline
\end{tabular}

Change of $\rho_{X}$ during modification +0.000204

The above data show the agreement in $B_{x}$ to be about $0.3 \mu \mathrm{g}$, which is somewhat poorer than average diver operation. Nevertheless, although the change in density associated with the process under examination amounted to only $5: 10^{5}$, the system reported this change to agreement of about $7 \frac{1}{2}$ percent.

This experiment was performed upon a crystal of only $250 \mathrm{mg}$. With larger samples, the reproducibility of $B_{X}$ would remain about constant, hence the reproducibility of values of density would be much improved.

\section{General Comments}

Although our work was not primarily din ected to evaluation of diver performance as a function of diver characteristics, the following comments may be of interest:

(A) We were never successful in working with Pyrex divers. Although the ones we tried out were always thoroughly annealed after fabrication, we never were able to achieve stability of much better than $\pm 10 \mu \mathrm{g}$.

(B) The sensitivity of the sytem may be crudely defined as $(-) \Delta B / \Delta P_{E}$, that is the indicated change in apparent mass per unit change in equilibrium pressure. Defined thus, the sensitivity of the diver reported on was about $1 / 12 \mu \mathrm{g} / \mathrm{g}$ change in $P_{E}$. We experimented upon highly compressible forms in which sensitivity was $10 \mu \mathrm{g} / \mathrm{g}$, and also upon structures with compressibilities so small that sensitivity approached $0.003 \mu \mathrm{g} / \mathrm{g}$. We found that the reproducibility decreased as the divers had extremely small or extremely large values of sensitivity. For the extremely sensitive structures we experienced difficulty in obtaining hydrostatic balance, and for the relatively insensitive structures, zero drift was most annoying.

(C) The system is quite sensitive to vibration and the mechanical shock associated with closing doors, etc. Spaepen also reported this vibration sensitivity and described his efforts to minimize it. Our experi- 
ment was conducted on a massive pier which had previously been used to support a high sensitivity balance used in the NBS mass calibration program. A vibration survey conducted prior to the experiment indicated that at $30 \mathrm{~Hz}$, the vibrations were about $6 \times 10^{-4} \mathrm{~g}$, decreasing somewhat at night. Our best work was done at night and on weekends.

(D) Many experimenters working with other buoyant devices have reported difficulty in achieving smooth "lift-off" of the buoyant structure from an alining cone at the bottom. We found that a blunt tip at the bottom of the quartz diver moved nicely out of a chromium-plated brass cone whose radius was somewhat greater than the quartz. We experimented with cones of both Pyrex and sapphire with poor results.

(E) In a private communication Spaepen informed us that a newly fabricated diver is rarely stablethat a one or two months aging period is called for. This has also been our experience. We believe that annealing the quartz diver would probably reduce this aging period.

(F) A major uncertainty in all hydrostatic weighing is caused by the adherence of gas to the surfaces of the load. An air bubble large enough to displace $1 \mu \mathrm{g}$ of water is easily detected visually and easily removed. An equal amount of gas dispersed among several hundred (or thousand?) bubbles would be impossible to detect (without a priori knowledge of the density of the material being hydrostatically weighed). This could lead to serious systematic errors in the values of density calculated from observed data. In order to randomize the surface trapped air, we always remove all loads (both standards and unknowns) between each hydrostatic experiment and thoroughly dry and reclean them. A stable volume of gas adhering to the surfaces of the diver body is less annoying, since its chief effect is to change the values of $C_{1}$ and $G$ which are determined in each experiment.

(G) In changing diver loads the portion of the tools used which come into contact with the loads are kept continuously immersed in water, never allowing them to come into contact with air. In this way we minimize the likelihood of transferring air from the tools to the loads.

(H) Generally, a perfectly cylindrical diver body will be insufficiently compressible for practical diver operation. Our method of achieving the desired compressibility is to measure $\Delta G / \Delta P$ on a newly constructed diver in its initial cylindrical form. We then partially flatten the cylindrical walls by flame treatment in small increments, measuring $\Delta G / \Delta P$ after each operation. This process is continued until the desired sensitivity is attained. Figure 1 shows this partially flattened section.

The authors take pleasure in acknowledging the generous assistance provided by numerous members of the NBS staff.

Paul Pontius, H. S. Peiser, A. G. MeNish, and W. A. Wildhack have provided encouragement, guidance, and support during the entire effort. J. M. Frankland, Dan P. Johnson, J. L. Cross, Harry Matheson, Malcolm Morse, John Pararas, and R. D. Deslattes gave us expert consultation in their special fields.

Enrico Deleonibus devised many special glassblowing techniques required in the fabrication of the quartz divers. Richard Smith and F. Ferensic performed the intricate machine work required and provided many ideas embodied into the system.

W. S. Brower of the NBS Crystal Chemistry group provided the rutile crystals and E. L. Warrick of the Dow Corning Company furnished the silicon crystals.

The work was performed with partial support of the Advanced Research Projects Agency.

\section{References}

[1] Chairulli, P. and F. M. Chilton, Investigations on the Cartesian diver balance, (private communication, 1956).

[2] Haller, W. K., and G. L. Calcamuggio, Apparatus for the measurement of extremely small weight, volume, and density changes, Rev. Sci. Instr. 26, No. 11, p. 1064 (1955).

[3] Spaepen, J., Application of the float method for precision measurement of the density of water and for small samples of solids, Mededel. Koninkl. Vlaam. Akad. Wetenschap. Belg. 19, No. 5 (1957).

[4] Johnson, D. P., D. Steele, and M. DeNovens, Measurement of drift and recovery in aircraft altimeters, (private communication, 1953).

[5] Brombacher, W. G., D. P. Johnson, and J. L. Cross, Mercury barometers and manometers, NBS Mono. 8 (1960).

(Paper 69C3-202) 